\title{
Ventilatory efficiency and its clinical and prognostic value in adults with cystic fibrosis
}

\author{
Pierantonio Laveneziana ${ }^{1,2}$ and Paolo Palange ${ }^{3}$
}

\author{
Number 10 in the Series "Ventilatory efficiency and its clinical prognostic value in cardiorespiratory \\ disorders" \\ Edited by Pierantonio Laveneziana and Paolo Palange
}

\begin{abstract}
${ }^{1}$ Sorbonne Université, INSERM, UMRS1158 Neurophysiologie Respiratoire Expérimentale et Clinique, Paris, France. ${ }^{2}$ AP-HP, Groupe Hospitalier Universitaire APHP-Sorbonne Université, sites Pitié-Salpêtrière, Saint-Antoine et Tenon, Service des Explorations Fonctionnelles de la Respiration, de l'Exercice et de la Dyspnée (Département R3S), Paris, France. ${ }^{3}$ Dept of Public Health and Infectious Diseases, Sapienza University of Rome, Rome, Italy.
\end{abstract}

Corresponding author: Pierantonio Laveneziana (pierantonio.laveneziana@aphp.fr)

\author{
Shareable abstract (@ERSpublications) \\ Cardiopulmonary exercise testing is a useful tool to assess the mechanisms of exercise intolerance \\ in individual patients with CF and may have treatment and prognostic implications. \\ https://bit.ly/3uH0oq9
}

Cite this article as: Laveneziana P, Palange P. Ventilatory efficiency and its clinical and prognostic value in adults with cystic fibrosis. Eur Respir Rev 2021; 30: 200395 [DOI: 10.1183/16000617.0395-2020].

Copyright (The authors 2021

This version is distributed under the terms of the Creative Commons Attribution NonCommercial Licence 4.0. For commercial reproduction rights and permissions contact permissions@ersnet.org

Received: 23 Dec 2020 Accepted: 8 May 2021

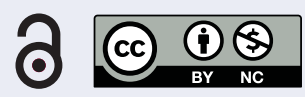

\section{Abstract}

Cystic fibrosis, due to the absence or abnormal function of the cystic fibrosis transmembrane conductance regulator, is the most common life-limiting autosomal recessive genetic disorder among the Caucasian population. The lungs are particularly affected due to thick and tenacious mucus causing parenchymal anomalies ranging from bronchiectasis, progressive airflow limitation, respiratory infections, lung destruction and ultimately respiratory failure. Despite the remarkable advances in treatment that have greatly improved survival, most patients experience progressive exercise curtailment, with the consequence that a growing number of patients with cystic fibrosis will be referred for exercise-based evaluations in the forthcoming years. Cardiopulmonary exercise testing, in particular, is a useful tool to assess the mechanisms of exercise intolerance in individual patients that may have treatment and prognostic implications. In this review, we will focus on ventilatory efficiency and its clinical and prognostic value in adults with cystic fibrosis.

\section{Introduction}

This review belongs to the series on "Ventilatory efficiency and its clinical and prognostic value in cardiorespiratory disorders". The review is addressed to clinicians, physiologists and researchers to encourage them to get acquainted with cardiopulmonary exercise testing (CPET) in order to help and orient the clinical decision concerning adult individual patients with cystic fibrosis (CF). CF is due to the absence or abnormal function of the cystic fibrosis transmembrane conductance regulator (CFTR) and represents the most common life-limiting autosomal recessive genetic disorder among the Caucasian population. Due to the systemic nature of the disease, many organs are involved; the lungs, however, are primarily affected because of progressive chronic obstructive anomalies, secondary to the very thick and tenacious mucus that leads to bronchiectasis with resultant respiratory infections, progressive airflow limitation and lung destruction and ultimately respiratory failure. Recent major advances in CF treatments have significantly prolonged life expectancy in patients with CF in the last 20 years to the extent that nowadays there are more adults who are affected by the disease than children. Despite this, patients with CF experience progressive exercise curtailment that typically worsens over time, the major consequence of this being that more and more patients will be referred for CPET evaluation in the future. Exercise (in) tolerance is a well-established indicator of prognosis in CF [1, 2], as is the case in several chronic cardiac 
and pulmonary diseases [3, 4]. This is the reason why clinicians should encourage patients with CF to exercise on a regular basis and be active from a physical activity standpoint, along with keeping a good nutritional state. This is in line with the results of numerous studies that have clearly pointed out that the rate of decline in lung function can be reduced or slowed by having patients with CF engage in regular exercise and physical activity along with a good nutritional state. In addition, the rate of pulmonary exacerbations can be drastically reduced with exercise training programmes and pulmonary physiotherapy. This review outlines the role of exercise testing, mainly CPET, in assessing the functional status and the prognosis of adult patients with CF, with a particular focus on the ventilatory efficiency and its clinical and prognostic value.

Functional evaluation of adults with CF: the role of CPET and field tests

It is well established that measurements of resting spirometry-related indices, such as forced expiratory volume in $1 \mathrm{~s}\left(\mathrm{FEV}_{1}\right)$, are not able to predict exercise (in)tolerance in patients with $\mathrm{CF}$ [3-5]. Exercise performance should, therefore, be assessed particularly in the mild to moderate phases of CF, and CPET is the gold standard tool for this assessment, as is the case in several disorders [3, 4]. CPET not only enables maximal or peak oxygen uptake $\left(V^{\prime} \mathrm{O}_{2}\right.$ peak) to be determined but it also sheds light upon the mechanisms of exercise curtailment, such as ventilatory limitation, cardiovascular limitation and metabolic/muscle limitation [3, 4].

When CPET equipment is not accessible, field tests can be used. Field tests are however less accurate than CPET in evaluating the extent of exercise curtailment and the responses to interventions [4]. Nonetheless, two measures obtained by field tests have been used in studies enrolling patients with CF to assess the response to therapeutic intervention, such as the distance covered during the 6-min walk test (6MWT) and the number of steps climbed during a 3-min step test [6]. Interestingly, СHETTA and co-workers showed that adult patients with CF and mild to moderate lung disease, when compared with healthy controls, did not differ in walk distance and in pulse rate when they performed the 6MWT, but differed in oxygen saturation and breathlessness perception [7].

An emerging field test is the Shuttle Test: while the 6MWT is a self-paced walking test that approximately correlates with $V_{\mathrm{O}_{2}}^{\prime}$ peak measured during CPET, the Shuttle Test is an incremental externally paced audio signal whose highest speed better correlates with the $V_{\mathrm{O}_{2}}^{\prime}$ peak measured during CPET [8] than with 6MWT. This information is lacking in adults with CF.

\section{Factors limiting exercise tolerance in CF detected at CPET}

Ventilatory limitation (e.g. low $\mathrm{FEV}_{1}$ ) is usually the major factor limiting exercise in patients with $\mathrm{CF}$ who are in their advanced phase of the disease. However, deconditioning and poor nutritional condition may also represent important factors limiting or contributing to exercise curtailment. Exertional dyspnoea and leg discomfort are usually the most common reasons for stopping exercise in patients with CF, albeit no difference has recently been found in frequency of these two symptoms in curtailing exercise when comparing patients with CF with healthy subjects [9]. Peripheral factors such as skeletal muscle dysfunction presenting with decreased muscle mass/force may be responsible for reduced aerobic capacity and premature lactate production that, all together, may promote a rise in ventilatory demand during exercise. Dynamic lung hyperinflation on exertion may occur in patients with CF [10] as is the case in other chronic respiratory disorders such as COPD. The development of dynamic lung hyperinflation, measured by the decrease of inspiratory capacity, should be reported [11] as it highly correlates with dyspnoea [12, 13] and is amenable to treatment with bronchodilators [12, 13]. Arterial oxygen desaturation may occur during exercise [3]. In other disorders such as COPD and lung fibrosis, arterial oxygen desaturation usually develops on exertion when $T_{\mathrm{LCO}} / D_{\mathrm{LCO}}$ (transfer factor of the lung for carbon monoxide/diffusing capacity of the lung for carbon monoxide) is $<50 \%$ predicted [3]; in addition, arterial oxygen desaturation is more frequent during walking than cycling in COPD [14]. In some patients affected by CF who experience peripheral muscle dysfunction, such as deconditioning and poor muscle energetics, anaerobic metabolism may kick in early in the course of exercise leading to early lactate production [3]. Last but not least CPET clearly defines the extent of exercise curtailment (i.e. $V_{\mathrm{O}_{2}}^{\prime}$ peak), predicts prognosis $[1,2]$ and sheds light on the mechanisms of reduced exercise tolerance in patients with CF.

The physiological, clinical and prognostic value of the ventilatory efficiency in adults with CF The steepness with which minute ventilation $\left(V_{\mathrm{E}}^{\prime}\right)$ increases in response to and with respect to pulmonary carbon dioxide output $\left(V^{\prime} \mathrm{CO}_{2}\right)$ defines the appropriate ventilatory response to exercise (i.e. ventilatory efficiency) and depends on how and to what extent $V_{\mathrm{E}}^{\prime}$ obeys pulmonary gas exchange and acid-base regulations [15]. Thus, three variables drive the ventilatory demand/response of/to exercise: the rate of $V^{\prime} \mathrm{CO}_{2}$, the set-point at which arterial $\mathrm{CO}_{2}$ partial pressure $\left(P_{\mathrm{aCO}_{2}}\right)$ is regulated, and the physiological dead 
space fraction of tidal breath $\left(V_{\mathrm{D}} / V_{\mathrm{T}}\right)$, as described by the modified Bohr equation [15]:

$$
\frac{V_{\mathrm{E}}^{\prime}}{V_{\mathrm{CO}_{2}}^{\prime}}=\frac{863}{P_{\mathrm{aCO}_{2}} \times\left(1-V_{D} / V_{T}\right)}
$$

In the ideal lung, at a regulated $P_{\mathrm{aCO}}$, there is homogeneous evenness of lung ventilation to perfusion $\left(V^{\prime} / Q^{\prime}\right)$. With unevenness, efficiency of lung gas exchange is impaired, and this necessitates a rise in $V^{\prime}{ }_{E}$ for a given $V_{\mathrm{CO}_{2}}^{\prime}$ to maintain a stable $P_{\mathrm{aCO}}$. This is the reason why exercise ventilatory efficiency is best described by the $V_{\mathrm{E}}^{\prime} / V^{\prime} \mathrm{CO}_{2}$ relationship. This relationship is explained by four indices [16]: its steepness (the $V^{\prime}{ }_{\mathrm{E}} / V^{\prime} \mathrm{CO}_{2}$ slope), its intercept on the y-axis, the absolute ratio measured at its lowest value during CPET (nadir) and the absolute ratio measured at anaerobic/lactate threshold, as thoroughly reviewed in the fourth review in this series by WARD [17]. In order to refrain from underestimating ventilatory (in)efficiency, a cautious interpretation of these indices is essential in specific clinical populations, such as those presenting with respiratory mechanical constraints, for example, COPD [18]. Ventilatory (in)efficiency has been demonstrated to be clinically useful in exploring the pathophysiological mechanisms of exercise intolerance, in defining the functional impact of cardiopulmonary diseases on gas exchange during CPET, in evaluating disease progression, in identifying comorbidities, and in assessing therapeutic intervention in COPD [19]. In addition, ventilatory (in)efficiency is a well-established independent prognostic factor in numerous cardiorespiratory disorders, such as pulmonary fibrosis, pulmonary hypertension and chronic heart failure [4, 15]. Therefore, it would not be surprising that ventilatory efficiency would hold important clinical and prognostic information in a complex disease such as CF characterised by chronic inflammation and thus remodelling of the airways, which result in frequent pulmonary exacerbations, progressive worsening in lung function and $V^{\prime} / Q^{\prime}$ unevenness. Recently, Di PAOLO et al. [20] have pointed out that altered ventilatory efficiency is a pathophysiological hallmark of CF and that it could hold a greater sensitivity than lung function tests in identifying heterogeneity of ventilation. They provided a thorough frame of reference pertaining to indices of ventilatory efficiency in CF adults presenting with normal to moderately altered lung function and pointed out that ventilatory efficiency was impaired even in adult patients with CF with normal resting lung function (figure 1) [20]. They also stressed the importance of measuring the intercept to properly illustrate ventilatory inefficiency as the severity of lung disease increases (figure 2) [20]. Finally, they pointed out that ventilatory inefficiency seems to be impacted rather by an altered $V_{\mathrm{D}} / V_{\mathrm{T}}$ than by the occurrence of dynamic lung hyperinflation or by an abnormal $\mathrm{CO}_{2}$ set-point, thus ruling out the potential contribution of dynamic lung hyperinflation and chemosensitivity in defining the ventilatory demand/efficiency in adult patients with CF [20]. Altered $V_{\mathrm{D}} / V_{\mathrm{T}}$ in CF results from both large and small airway remodelling [21, 22]. Di PAOLO et al. [20] demonstrated that ventilatory inefficiency is independent from resting lung functional impairment and, in addition, is altered even in patients in which resting spirometry may underestimate the actual severity of lung disease. This is an important information because continuous deterioration in lung function is a typical characteristic in the natural evolution of CF, and following up its progression is instrumental in identifying patients who necessitate more robust therapeutic intervention to decelerate this immutable process [23]. Measuring ventilatory efficiency or inefficiency is therefore a useful and emerging tool in clinical practice, along with other indices such as the lung clearance index (LCI), pulmonary magnetic resonance imaging (MRI) and high-resolution computed tomography (HRCT).

The LCI is a measure of ventilation distribution inhomogeneity which can be calculated with the multiple breath washout method [24]. LCI is able to detect pathological abnormalities within the peripheral airways, even in many patients with $\mathrm{CF}$ with normal $\mathrm{FEV}_{1} \%$ in early stages of their lung disease [25-27]. LCI can therefore inform clinicians on the "silent zone of the lung", meaning the pathological lung compartments that are usually not detectable by conventional lung function tests such as spirometry [25-27]. Therefore, LCI is of great value for lung diseases such as CF [28], for which early detection of structural injuries and immediate interventions are instrumental to slow the progression of the disease [25-27]. It has been shown that, in most cases, a normal LCI can rule out the presence of anomalies observed at HRCT [29, 30]. LCI has also been found to relate in particular to the extent of bronchiectasis, and the presence of mucus plugging and emphysema [31]. These findings may open to the suggestion of routine using of LCI as a reliable alternative to HRCT as a first line exam to rule out lung injury while minimising radiation exposure. Some studies have recently assessed the performance of pulmonary MRI using hyperpolarised gas among patients with CF and found a strong correlation between anomalies detected at MRI and abnormal LCI values [28, 32-36]. The extent of ventilatory efficiency alteration has been recently found to correlate with the degree of air trapping at HRCT scan but not with scores indicating airway disease such as bronchiectasis, mucous plugging and bronchial wall thickening [37], nor with the measures of transfer or diffusion capacity of the lung for carbon monoxide ( $T_{\mathrm{LCO}}$ or $\left.D_{\mathrm{LCO}}\right)$ [20]. This comes as a surprise given 

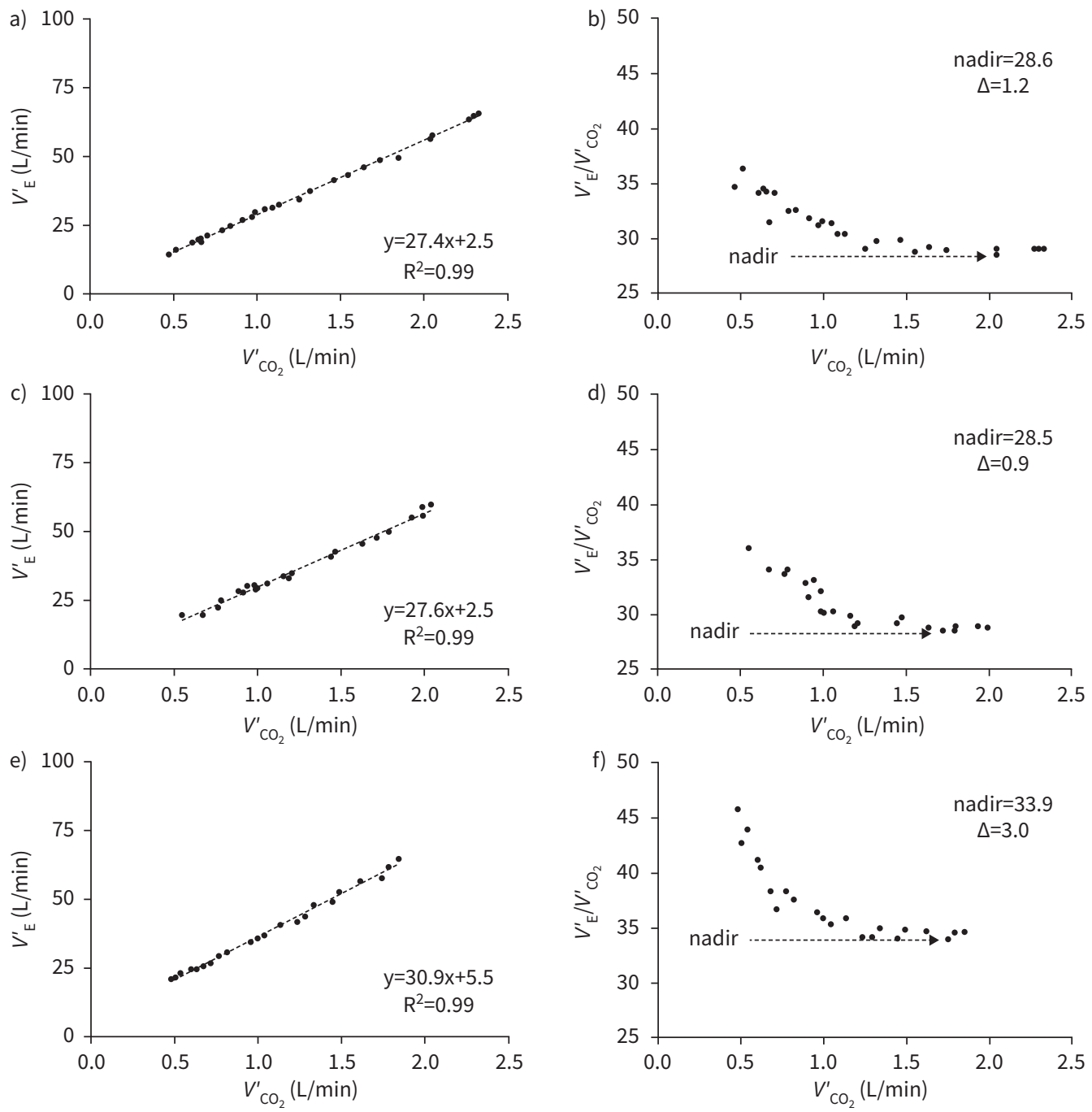

FIGURE 1 Representative cases of ventilatory inefficiency profiles in patients with cystic fibrosis with normal (a and $b$ ), mildly impaired ( $c$ and $d$ ) and moderately impaired (e and f) lung function. Each data point is the arithmetic mean of breath-to-breath values recorded over a $15 \mathrm{~s}$ period. $V_{\mathrm{E}}^{\prime}$ : minute ventilation; $V^{\prime} \mathrm{CO}_{2}:$ carbon dioxide output. $\Delta=$ nadir - slope difference. Reproduced from DI PAoLo et al. [20], with permission.

that $T_{\mathrm{LCO}} / D_{\mathrm{LCO}}$ is a recognised predictor of ventilatory inefficiency in COPD [38]. It is reasonable to think that the lower extent of pulmonary vascular and parenchymal destruction in CF might explain, at least in part, the absence of correlation between ventilatory (in)efficiency and $T_{\mathrm{LCO}} / D_{\mathrm{LCO}}$ in adults with CF. Higher dead space and lower tidal volume secondary to mechanical constraints induced by dynamic lung hyperinflation are deemed to play a fundamental role in CF. In addition, the lack of solid correlations between ventilatory (in)efficiency and resting lung function measures including $T_{\mathrm{LCO}} / D_{\mathrm{LCO}}$, clearly indicates that measures derived from CPET and resting lung function are complementary in CF population [20]. Despite the evidence of its clinical utility, CPET yet seems to be largely underused in CF. This seems true at least for its prognostic role in patients with CF, despite the past 30 years of clinical evidence collected on its prognostic utility [1, 39-41] and recently highlighted by HeBESTREIT et al. in a large multicentre study [2]. Eight years survival is three times greater in patients with CF presenting with $V_{\mathrm{O}_{2}}^{\prime}$ peak $>82 \%$ pred than in those presenting with low $V_{\mathrm{O}_{2}}^{\prime}$ peak $<58 \%$ pred [1]. In addition, mortality is increased among patients with CF presenting with a $V_{\mathrm{O}_{2}}^{\prime}$ peak $<32 \mathrm{~mL} \cdot \mathrm{min}^{-1} \cdot \mathrm{kg}^{-1}$ compared with those presenting with $V^{\prime} \mathrm{O}_{2}$ peak $>45 \mathrm{~mL} \cdot \mathrm{min}^{-1} \cdot \mathrm{kg}^{-1}$ [2]. HeBESTREIT et al. [2] in a large, international multicentre study confirmed that $V_{\mathrm{O}_{2}}^{\prime}$ peak and work rate peak were solid predictors of survival (over a 10-year period) and lung transplantation in patients with CF. 
a)

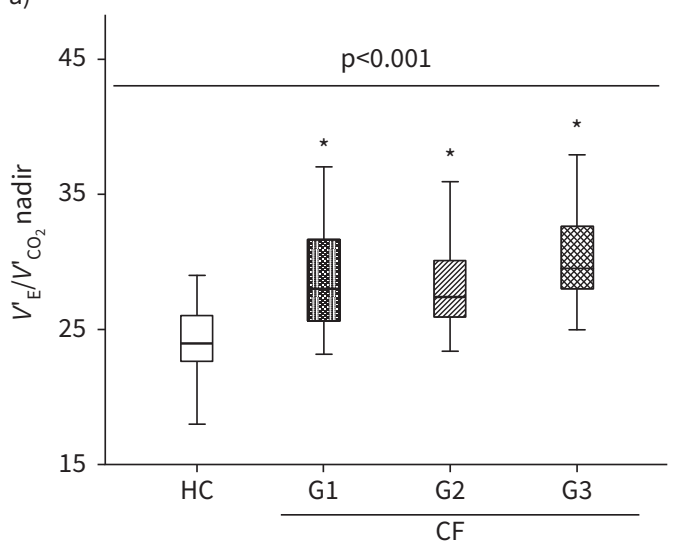

c)

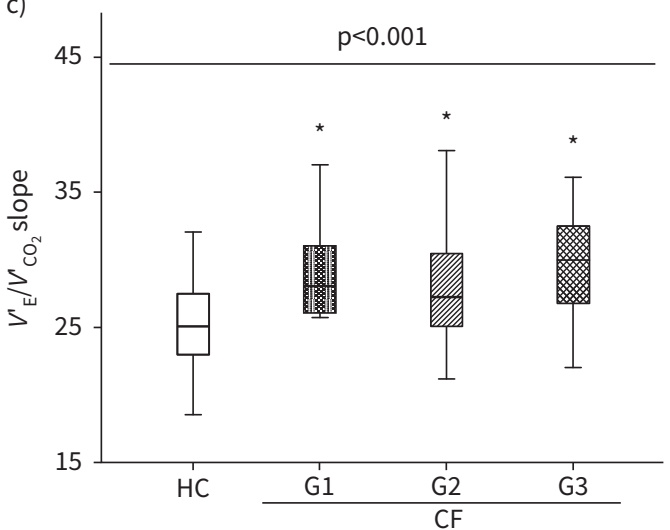

e)

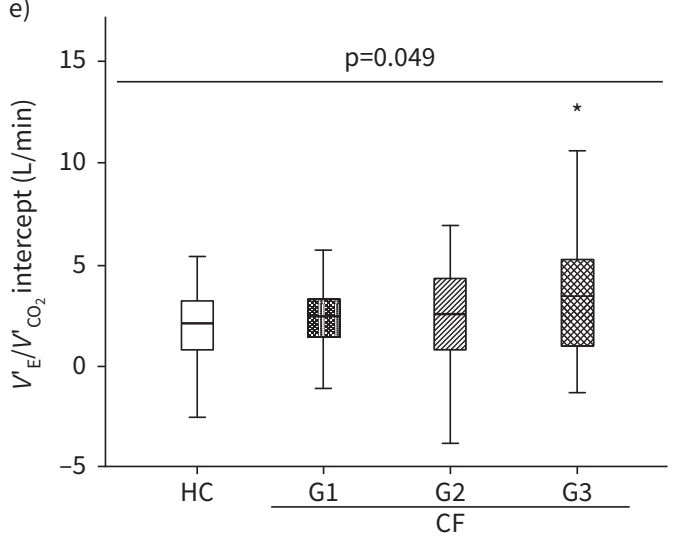

b)

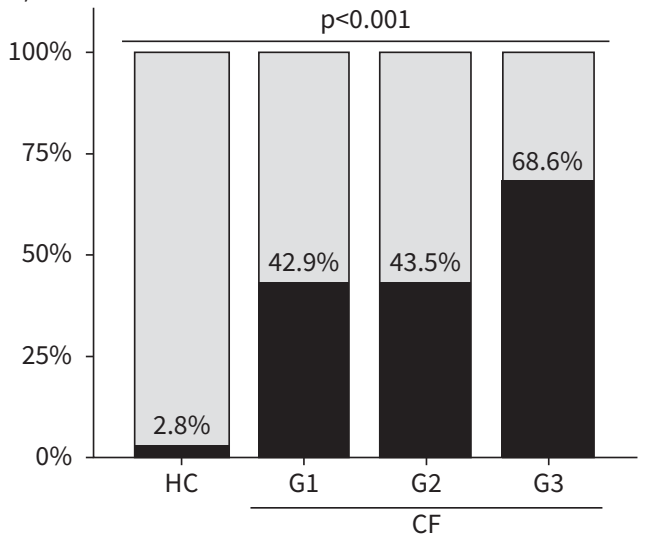

d)

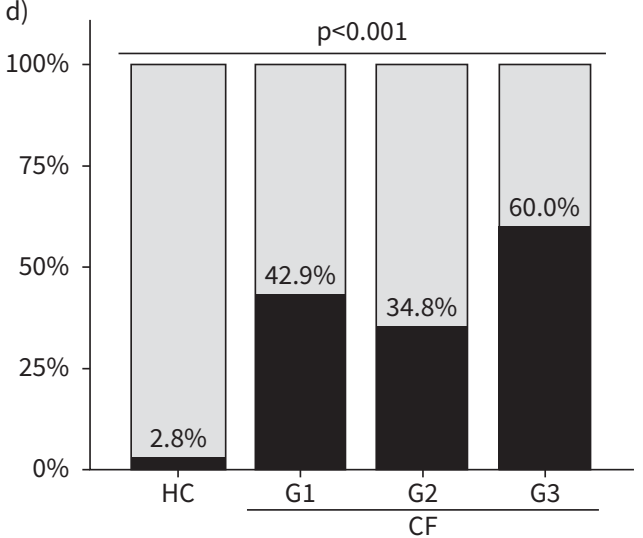

f)

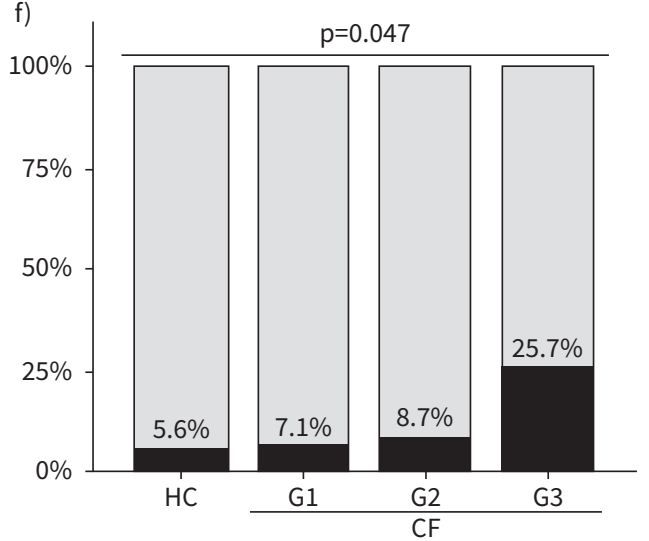

FIGURE 2 Comparison of $V_{E}^{\prime} / V^{\prime}{ }_{\mathrm{CO}_{2}}$ nadir (a), slope (c) and intercept (e) in patients with cystic fibrosis according to the severity of impairment to lung function and matched HC. Patients were divided into groups according to pulmonary function test results. G1: normal lung function: $\mathrm{FEV}_{1} / \mathrm{FVC} \geqslant 0.7, \mathrm{FEV}_{1} \geqslant 80 \%$ pred, and $\mathrm{FVC} \geqslant 80 \%$ pred; G2: mild impairment: not satisfying criteria for $\mathrm{G} 1$ and $\mathrm{FEV}_{1} \geqslant 70 \%$ pred; G3: moderate impairment: not satisfying criteria for $\mathrm{G} 1$ and $40 \% \leqslant \mathrm{FEV}_{1}<70 \%$ pred. Relative frequencies of nadir (b), slope (d), and intercept (f) above the upper limit of normality (ULN) estimated from the 95th percentile of HC distribution. ULN=28.5, 29.5, and $5.3 \mathrm{~L} \cdot \mathrm{min}^{-1}$ for nadir, slope, and intercept, respectively. $\mathrm{p}$-values intended for comparisons between all subgroups of participants. ${ }^{*}$ : $\mathrm{p}<0.05$ versus $\mathrm{HC}$, using a post hoc test. CF: cystic fibrosis; FEV ${ }_{1}$ : forced expiratory volume in $1 \mathrm{~s}$; FVC: forced vital capacity; $\mathrm{HC}$ : healthy controls; $V^{\prime} \mathrm{CO}_{2}$ : carbon dioxide output; $V^{\prime}$ : minute ventilation. Reproduced from Dı PAoLo et al. [20], with permission.

\section{Future directions and perspectives}

What about the prognostic role of ventilatory efficiency or inefficiency in adult patients with CF? This is still debated. Hebestreit et al. [2] did not find a correlation between the $V^{\prime}{ }_{\mathrm{E}} / V^{\prime} \mathrm{CO}_{2}$ slope and survival nor 
lung transplantation in their patients with $\mathrm{CF}$, but they found that $V_{\mathrm{E}}^{\prime} / V_{\mathrm{O}_{2}}^{\prime}$ and $V_{\mathrm{E}}^{\prime} / V^{\prime} \mathrm{CO}_{2}$, both at peak exercise, were solid and strong predictors of survival (over a 10-year period) and lung transplantation in their patients with CF [2]. Whether $V_{\mathrm{E}}^{\prime} / V^{\prime} \mathrm{O}_{2}$ and $V_{\mathrm{E}}^{\prime} / V_{\mathrm{CO}_{2}}^{\prime}$, both at peak exercise, are to be considered as indices of ventilatory efficiency (or inefficiency) is unclear and further well-designed prospective studies are needed to answer this question.

The data from the retrospective analysis by HeBestreit et al. [2] show that those patients with the worst prognosis had evidence of possible ventilatory constraint at peak exercise, with $V_{\mathrm{E}}^{\prime} / V^{\prime} \mathrm{CO}_{2}$ values similar to those with better resting lung function and better overall prognosis. This suggests that ventilatory efficiency might behave similarly to what is known for COPD patients [18], with a pseudo-normalisation of the slope and a progressive increase in the intercept instead [19]. Therefore, it is not surprising that the choice of the slope as the only marker of ventilatory efficiency in an outcome-based cluster analysis may be misleading and actually underestimate the possible prognostic relevance of ventilatory efficiency in a disease such as CF where ventilatory constraints are common in the most severe stages [20, 42].

In this regard, only two studies are available that focused in detail on the features of ventilatory efficiency in CF: one from Di PAOLo et al. in adults with CF [20], and another from Kampouras et al. [43] in 1120-year-old patients with CF accompanied by a commentary by NEDER et al. [42]. Although different for populations features, severity of lung diseases and the criteria used to define the severity of lung disease itself, both studies agree in showing that in $\mathrm{CF}$ the $V_{\mathrm{E}}^{\prime} / V^{\prime} \mathrm{CO}_{2}$ slope does not represent the best marker to describe the progressive impairment in ventilatory efficiency along with the worsening in lung function. However, the intercept had an obvious increasing trend among patients with more severe disease, as well as the nadir (see above), whose value was also found to be independent of the development of dynamic hyperinflation by Di PAOLo et al. [20].

In light of these considerations, it is our opinion that the effects of CF progression on ventilatory (in) efficiency, the physiological and structural determinants, as well as their prognostic value, remain an open field for future investigations.

\section{Summary}

$\overline{\mathrm{CF}}$ is the most common life-limiting autosomal recessive genetic disorder among Caucasians. The lungs are particularly affected due to the very thick and tenacious mucus causing parenchymal anomalies ranging from bronchiectasis, progressive airflow limitation, respiratory infections, lung destruction and ultimately respiratory failure. Despite the remarkable advances in treatment that greatly improved survival, most patients experience progressive exercise curtailment, with the consequence that a growing number of patients with CF will be referred to exercise-based evaluations in the forthcoming years. CPET in particular is a useful tool to assess the mechanisms of exercise intolerance in individual patients and may have therapeutic and prognostic implications. Measuring ventilatory efficiency or inefficiency (and their physiological and structural determinants) during CPET is a useful and emerging tool in clinical practice, but its prognostic role is still debated and needs further thorough investigation.

Provenance: Commissioned article, peer reviewed.

Previous articles in this series: No. 1: Laveneziana P, Di Paolo M, Palange P. The clinical value of cardiopulmonary exercise testing in the modern era. Eur Respir Rev 2021; 30: 200187. No. 2: Agnostoni P, Sciomer S, Palermo P, et al. Minute ventilation/carbon dioxide production in chronic heart failure. Eur Respir Rev 2021; 30: 200141. No. 3: Watson M, Ionescu MF, Sylvester K, et al. Minute ventilation/carbon dioxide production in patients with dysfunctional breathing. Eur Respir Rev 2021; 30: 200182. No. 4: Ward SA. Ventilation/carbon dioxide output relationships during exercise in health. Eur Respir Rev 2021; 30: 200160. No. 5: Collins SÉ, Phillips DB, Brotto AR, et al. Ventilatory efficiency in athletes, asthma and obesity. Eur Respir Rev 2021; 30: 200206. No. 6: Schaegger MR, Guenette JA, Jensen D. Impact of ageing and pregnancy on the minute ventilation/carbon dioxide production response to exercise. Eur Respir Rev 2021; 30: 200225. No. 7: Weatherald J, Philipenko B, Montani D, et al. Ventilatory efficiency in pulmonary vascular diseases. Eur Respir Rev 2021; 30: 200214. No. 8: Neder JA, Berton DC, Phillips DB, et al. Exertional ventilation/carbon dioxide output relationship in COPD: from physiological mechanisms to clinical applications. Eur Respir Rev 2021; 30: 200190. No. 9: Hager A. Minute ventilation/carbon dioxide production in congenital heart disease. Eur Respir Rev 2021; 30: 200178.

Conflict of interest: P. Laveneziana reports personal fees from Novartis France, Chiesi France and Boehringer France, outside the submitted work. P. Palange has nothing to disclose. 
References

1 Nixon PA, Orenstein DM, Kelsey SF, et al. The prognostic value of exercise testing in patients with cystic fibrosis. N Engl J Med 1992; 327: 1785-1788.

2 Hebestreit $\mathrm{H}$, Hulzebos EHJ, Schneiderman JE, et al. Cardiopulmonary exercise testing provides additional prognostic information in cystic fibrosis. Am J Respir Crit Care Med 2019; 199: 987-995.

3 Palange $\mathrm{P}$, Ward SA, Carlsen $\mathrm{KH}$, et al. Recommendations on the use of exercise testing in clinical practice. Eur Respir J 2007; 29: 185-209.

4 Puente-Maestu L, Palange P, Casaburi R, et al. Use of exercise testing in the evaluation of interventional efficacy: an official ERS statement. Eur Respir J 2016; 47: 429-460.

5 Bradley J, McAlister O, Elborn S. Pulmonary function, inflammation, exercise capacity and quality of life in cystic fibrosis. Eur Respir J 2001; 17: 712-715.

6 Kazmerski T, Orenstein DM. The ease of breathing test tracks clinical changes in cystic fibrosis. J Cyst Fibros 2012; 11: 383-386.

7 Chetta A, Pisi G, Zanini A, et al. Six-minute walking test in cystic fibrosis adults with mild to moderate lung disease: comparison to healthy subjects. Respir Med 2001; 95: 986-991.

8 Onorati P, Antonucci R, Valli G, et al. Non-invasive evaluation of gas exchange during a shuttle walking test vs. a 6-min walking test to assess exercise tolerance in COPD patients. Eur J Appl Physiol 2003; 89: 331-336.

9 Quon BS, Wilkie SS, Ramsook AH, et al. Qualitative dimensions of exertional dyspnea in adults with cystic fibrosis. J Appl Physiol (1985) 2016; 121: 449-456.

10 Nicholson TT, Barry PJ, Waterhouse DF, et al. Relationship between pulmonary hyperinflation and dyspnoea severity during acute exacerbations of cystic fibrosis. Respirology 2017; 22: 141-148.

11 Savi D, Di Paolo M, Simmonds N, et al. Relationship between daily physical activity and aerobic fitness in adults with cystic fibrosis. BMC Pulm Med 2015; 15: 59.

12 Dube B-P, Vermeulen F, Laveneziana P. Exertional dyspnoea in chronic respiratory diseases: from physiology to clinical application. Arch Bronconeumol 2017; 53: 62-70.

13 Laviolette L, Laveneziana P. Dyspnoea: a multidimensional and multidisciplinary approach. Eur Respir J 2014; 43: $1750-1762$.

14 Palange $\mathrm{P}$, Forte $\mathrm{S}$, Onorati $\mathrm{P}$, et al. Ventilatory and metabolic adaptations to walking and cycling in patients with COPD. J Appl Physiol (1985) 2000; 88: 1715-1720.

15 Weatherald J, Sattler C, Garcia G, et al. Ventilatory response to exercise in cardiopulmonary disease: the role of chemosensitivity and dead space. Eur Respir J 2018; 51: 1700860.

16 Sun XG, Hansen JE, Garatachea N, et al. Ventilatory efficiency during exercise in healthy subjects. Am J Respir Crit Care Med 2002; 166; 1443-1448.

17 Ward SA. Ventilation/carbon dioxide output relationships during exercise in health. Eur Respir Rev 2021; 30 : 200160.

18 Neder JA, Arbex FF, Alencar MC, et al. Exercise ventilatory inefficiency in mild to end-stage COPD. Eur Respir J 2015; 45: 377-387.

19 Neder JA, Berton DC, Arbex FF, et al. Physiological and clinical relevance of exercise ventilatory efficiency in COPD. Eur Respir J 2017; 49: 1602036.

20 Di Paolo M, Teopompi E, Savi D, et al. Reduced exercise ventilatory efficiency in adults with cystic fibrosis and normal to moderately impaired lung function. J Appl Physiol (1985) 2019; 59: 127-131.

21 Regamey N, Jeffery PK, Alton EW, et al. Airway remodelling and its relationship to inflammation in cystic fibrosis. Thorax 2011; 66: 624-629.

22 Stoltz DA, Meyerholz DK, Welsh MJ. Origins of cystic fibrosis lung disease. N Engl J Med 2015; 372: 351-362.

23 Grasemann H, Ratjen F. Early lung disease in cystic fibrosis. Lancet Respir Med 2013; 1: 148-157.

24 Robinson PD, Latzin P, Verbanck S, et al. Consensus statement for inert gas washout measurement using multiple- and single-breath tests. Eur Respir J 2013; 41: 507-522.

25 Robinson PD, Goldman MD, Gustafsson PM. Inert gas washout: theoretical background and clinical utility in respiratory disease. Respir Int Rev Thoracic Dis 2009; 78: 339-355.

26 Horsley A. Lung clearance index in the assessment of airways disease. Respir Med 2009; 103: 793-799.

27 Hall GL, Logie KM, Parsons F, et al. Air trapping on chest CT is associated with worse ventilation distribution in infants with cystic fibrosis diagnosed following newborn screening. PLoS ONE 2011; 6: e23932.

28 Hatziagorou E, Kampouras A, Avramidou V, et al. Toward the establishment of new clinical endpoints for cystic fibrosis: the role of lung clearance index and cardiopulmonary exercise testing. Front Pediatr 2021; 9 : 635719.

29 Ellemunter H, Fuchs SI, Unsinn KM, et al. Sensitivity of lung clearance index and chest computed tomography in early CF lung disease. Respir Med 2010; 104: 1834-1842.

30 Gustafsson PM, De Jong PA, Tiddens HA, et al. Multiple-breath inert gas washout and spirometry versus structural lung disease in cystic fibrosis. Thorax 2008; 63: 129-134.

31 Avramidou V, Hatziagorou E, Kampouras A, et al. Is lung clearance index ( $\mathrm{LCl}$ ) affected by the severity of lung disease in CF? J Pulm Respir Med 2017; 6: 392. 
32 Nyilas S, Bauman G, Sommer G, et al. Novel magnetic resonance technique for functional imaging of cystic fibrosis lung disease. Eur Respir J 2017; 50: 1701464.

33 Rayment JH, Couch MJ, McDonald N, et al. Hyperpolarised (129)Xe magnetic resonance imaging to monitor treatment response in children with cystic fibrosis. Eur Respir J 2019; 53: 1802188.

34 Smith L, Marshall H, Aldag I, et al. Longitudinal assessment of children with mild cystic fibrosis using hyperpolarized gas lung magnetic resonance imaging and lung clearance index. Am J Respir Crit Care Med 2018; 197: 397-400.

35 Stahl M, Wielputz MO, Graeber SY, et al. Comparison of lung clearance index and magnetic resonance imaging for assessment of lung disease in children with cystic fibrosis. Am J Respir Crit Care Med 2017; 195: 349-359.

36 Verbanck S, Vanderhelst E. The respective roles of lung clearance index and magnetic resonance imaging in the clinical management of patients with cystic fibrosis. Am J Respir Crit Care Med 2018; 197: 409.

37 Crisafulli E, Teopompi E, Luceri S, et al. The value of high-resolution computed tomography (HRCT) to determine exercise ventilatory inefficiency and dynamic hyperinflation in adult patients with cystic fibrosis. Respir Res 2019; 20: 78.

38 Jones JH, Zelt JT, Hirai DM, et al. Emphysema on thoracic CT and exercise ventilatory inefficiency in mild-to-moderate COPD. COPD 2017; 14: 210-218.

39 Moorcroft AJ, Dodd ME, Webb AK. Exercise testing and prognosis in adult cystic fibrosis. Thorax 1997; 52 : 291-293.

40 Stevens D, Stephenson A, Faughnan ME, et al. Prognostic relevance of dynamic hyperinflation during cardiopulmonary exercise testing in adult patients with cystic fibrosis. J Cyst Fibros 2013; 12: 655-661.

41 Tantisira KG, Systrom DM, Ginns LC. An elevated breathing reserve index at the lactate threshold is a predictor of mortality in patients with cystic fibrosis awaiting lung transplantation. Am J Respir Crit Care Med 2002; 165: 1629-1633.

42 Neder JA, Di Paolo M, O'Donnell DE, et al. On the complexities of measuring exercise "ventilatory efficiency" in obstructive lung diseases. Pediatr Pulmonol 2020; 55: 280-282.

43 Kampouras A, Hatziagorou E, Avramidou V, et al. Ventilation efficiency to exercise in patients with cystic fibrosis. Pediatr Pulmonol 2019; 54: 1584-1590. 